\title{
Experience-Dependent Color Constancy in Guppies (Poecilia reticulata)
}

\author{
I.E. Intskirveli, M.O. Roinishvili and A.R. Kezeli \\ Laboratory of Physiology of Vision, I. Beritashvili Institute of Physiology, Georgian \\ Academy of Sciences. 14, L. Gotua St., Tbilisi 380060, Georgia
}

\begin{abstract}
SUMMARY
We investigated the ability to recognize the color of surfaces in fish (Poecilia reticulata), bred from birth in conditions of artificial light with constant spectral content. The capacity for color constancy significantly deteriorated when compared that to the control group. Further alteration of lighting conditions and transfer into natural daylight conditions restored the suppressed function to its normal level. We suggest that the color constancy function belongs in the visual system-response functions, the full development of which requires the accumulation of individual visual experience.
\end{abstract}

\section{KEYWORDS}

color constancy, visual experience, fish

\section{INTRODUCTION}

In the period of postnatal development, the environment plays a key role in normal anatomical and physiological formation of the visual system. Studies in mammals, including humans, have shown that an anomalous visual medium can

Reprint requests to: Irakli Intskirveli Lab.of Physiology of Vision, I.Beritashvili Institute of Physiology, 14 Gotua St., 380060 Tbilisi; e-mail: irakli_i@yahoo.com significantly deteriorate visual function (Boothe et al., 1985; Movshon, Van Sluyters, 1981; Sherman \& Spear, 1982; Brown, 1990; Brown \& Teller, 1989; Teller \& Bornstein, 1987). Early deprivations result in abnormal spectral sensitivity, color opponency (certain colors appear to be mutually exclusive), and so on (Jacobs \& Neitz, 1984; McCourt \& Jacobs, 1983). Yet, the problem is far from clarified because the system's reaction to a specific stimulation is manifested at both the receptor and the post-receptor level. Alteration of the spectral content of illumination can induce changes in the photoreceptors that compensate illumination alterations (Kröger et al., 1999) Indeed, in such a case, detection of changes in the central processes of information evaluation will be hampered. This is especially true for data obtained in behavioral experiments, which may explain the existing controversies (Boothe et al., 1975; Brenner et al., 1985; Di et al., 1987; Brenner et al., 1990; Petry \& Kelly, 1991; Brenner et al., 1983; McCourt \& Jacobs, 1983; Peterson, 1961; Mecke, 1983).

The phenomenon of color constancy, defined as the ability of a vision system to perceive constant surface colors regardless of lighting conditions, is one of the most important mechanisms of the color vision system. The perfect functioning of such mechanisms is essential for the correct detection of a surface color and adequate solution of a task; which is vitally significant for an animal living in a natural habitat. 
The purpose of our investigation was to assess whether the individual visual experience of the early period of life influences the development of the color constancy function. For this kind of experiment, fish are versatile subjects because they have excellent color vision (Wheeler, 1982). The capacity for color discrimination determines the mode of life in most fish, providing for their behavioral peculiarities, reproduction, the ability to defend themselves against predators, and so on.

In cyprinid fish, color constancy was described by Burkamp (1923), Dimentman et al. (1972), and Ingle (1985), whereas Herter (1950) described the phenomenon of simultaneous color contrast. Dörr and Neumeyer $(1997,2000)$ made the first quantitative investigations of such phenomena In goldfish. Recently, similar results were obtained in both goldfish and man (Neumeyer at al., 2002) during investigations on the influence of surround size and lightness on color constancy.

As experimental subjects in our studies, we chose guppies (Poecilia reticulata), whose visual system is adapted to the habitat and to behavioral peculiarities. Guppies dwell mostly in the upper, well-illuminated layers of the water. Their ecology, genetics, and behavioral repertory have been studied in detail (Endler, 1978, 1983).

\section{EXPERIMENTAL}

Two groups of the laboratory-bred guppies were used in experiments. All fish were housed in similar aquariums and were fed a similar diet and had the same maintenance and care. The only difference was different conditions of illumination.

\section{Experimental groups}

Group I, reared under natural daylight illumination. Four fish, 3 month of age, were assigned to Group I. These fish were bred and raised in a color-saturated environment (in the laboratory). The aquarium, which served as the fish house, was illuminated with natural daylight. During the dark periods of day in the winter season, an additional several hours illumination was provided with an incandescent $100-\mathrm{W}$ bulb.

Group II, reared under a constant source of artificial illumination. Group II also comprised four Guppies of the same age, bred and raised in similar visual surroundings, but the sole and only source of illumination for these fish was an incandescent $100 \mathrm{~W}$ bulb, which was turned on and off according to the regular day-and-night regime ( $14 \mathrm{~h}$ day $/ 10 \mathrm{~h}$ night).

Experiments were carried out in a $35 \mathrm{~cm}$ long, $19 \mathrm{~cm}$ wide, and $20 \mathrm{~cm}$ deep aquarium having walls covered with white paper. Pieces of red and green paper, $12.5 \times 12.5 \mathrm{~cm}$, served as the stimuli to be discriminated. The reflection spectral curves of the stimuli are shown in Fig. 1. A slide projector with an incandescent $100-\mathrm{W}$ bulb served as the source of illumination; the light from the projector was aimed at a tilted, diffusely reflecting screen positioned over the aquarium (Fig. 2). The maximal illumination on the stimulus surface was $65 \mathrm{Lx}$. In both living and experimental aquariums, water temperature was maintained at 24 to $27^{\circ} \mathrm{C}$, with temperature differences never exceeding $1^{\circ} \mathrm{C}$.

The fish were transferred into the experimental aquarium 3 to $5 \mathrm{~min}$ before the experiment onset, thus allowing the animals to adapt to new conditions and to adjust to the thermal regime.

The experiments in both groups were carried out according to a similar scheme: at the first stage of experiments (source of illumination a $100 \mathrm{~W}$ incandescent bulb, illumination on the stimulus surface $65 \mathrm{Lx}$.), the fish learned to discriminate the colors. On the opposite walls of the aquarium, the guppies were simultaneously presented with differential stimuli, which alternated from trial to trial in a random order. To receive a reward (live food), the fish had to swim toward the red stimulus. 


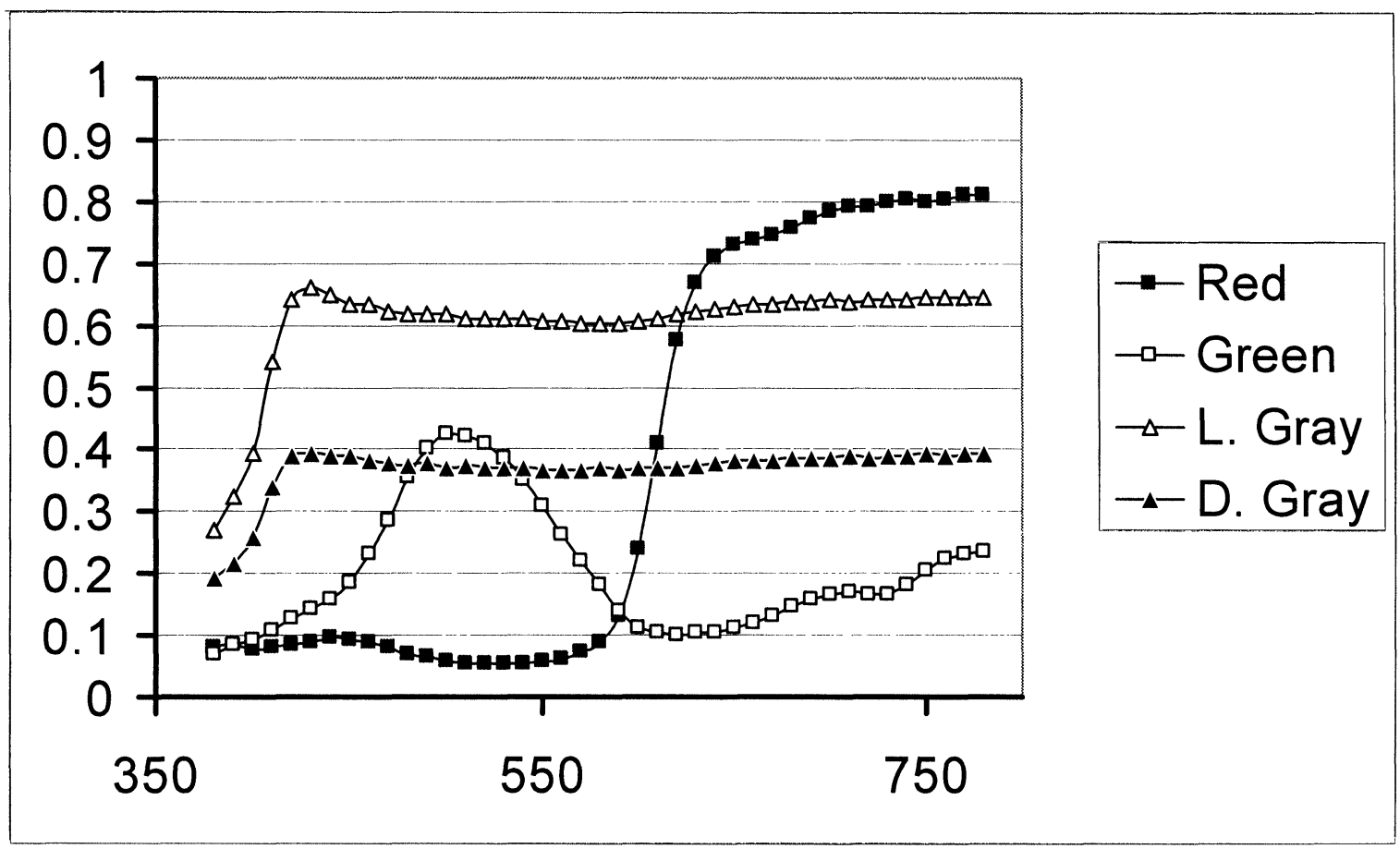

Fig. 1: Reflection curves of the differentiated (red and green) and test (light gray and dark gray) papers.

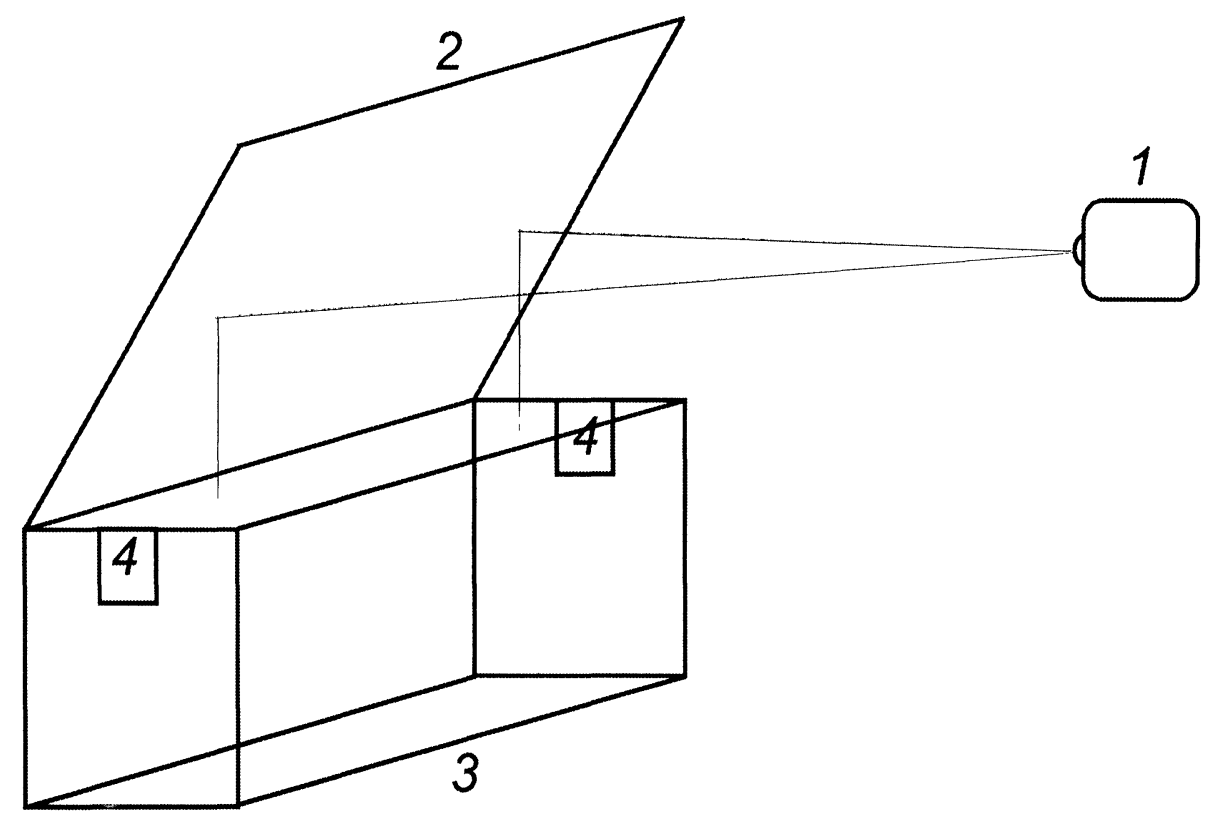

Fig. 2: Design of experimental setup. 1 - light source, 2 - reflecting screen, 3 - aquarium, 4 - stimuli. 
After reinforcement, the stimulus was withheld. The interval between the stimuli presentations was 3 min. Each experimental session consisted of 10 to 15 presentations. To ensure that the fish could make a color choice in different illumination conditions, the total illumination in different trials was altered randomly in $5 \mathrm{Lx}$ steps, in both directions from low $(15 \mathrm{Lx})$ to maximal $(60 \mathrm{Lx})$ values. As soon as the percentage of correct choices, notwithstanding the illumination level, exceeded $70 \%$, the next series of experiments commenced. In this series of experiments the standard filters from the color optic glass kit (GOST 9411-66, USSR) were used. With the aid of these filters the stimuli were illuminated with mixed lights of red (red filter Fig. 3) and green (green filter Fig. 3) sources in various proportions. Therefore, the fish should make their choice in conditions of altered illumination.

To exclude the possibility that the fish had learned the colors under the novel conditions of illumination, certain alterations were made in the experimental design: in this case, even if fish made correct choice at mixed illumination, no reinforcement was provided. Each nonreinforced trial at mixed illumination was followed by 4 to 5 trials at standard illumination with reinforcement of correct choices. Such a strategy significantly prolongs the data acquisition but is worthwhile from the significance standpoint.

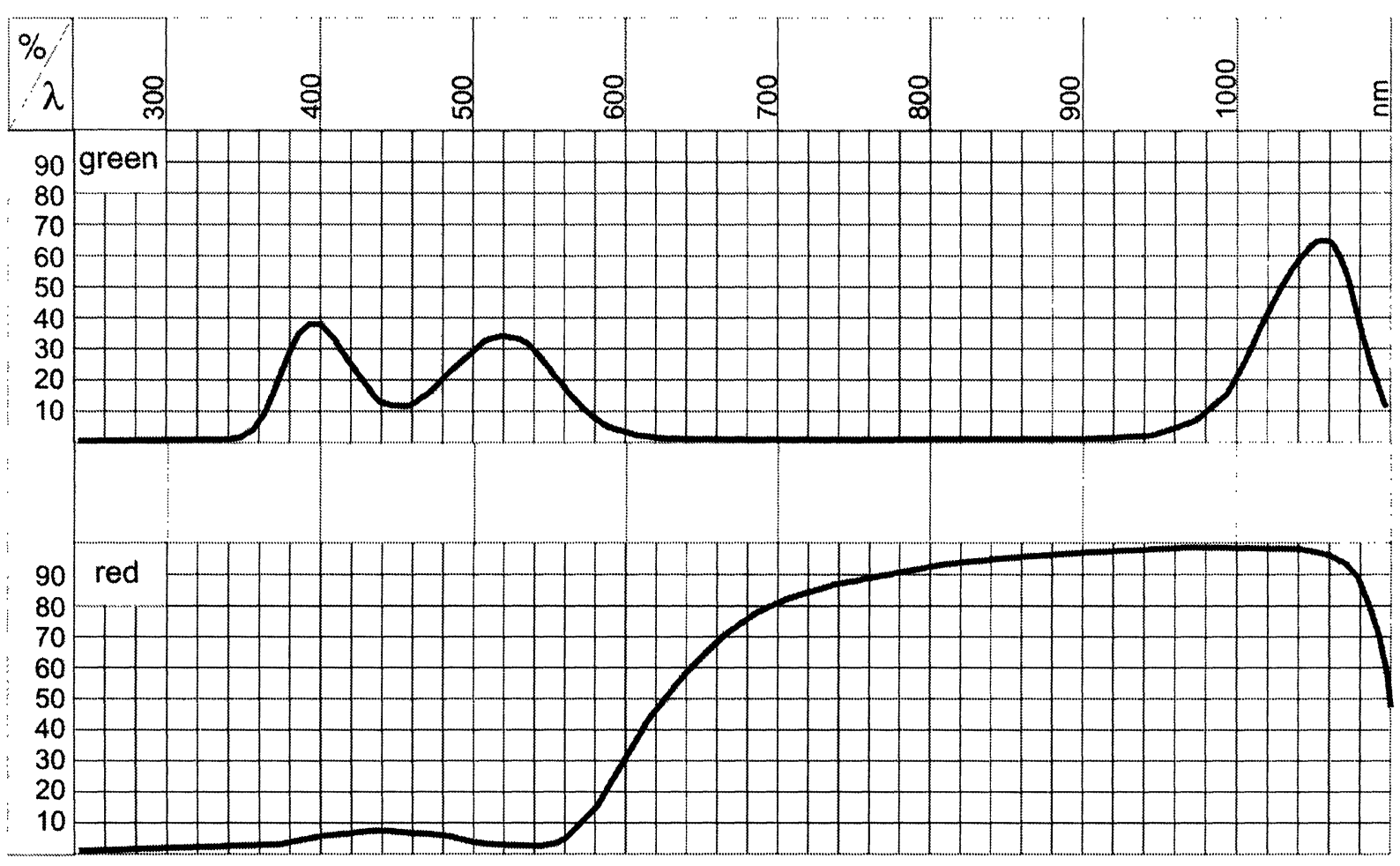

Fig. 3: Spectral curves of transmission coefficients $\left(\tau_{\lambda}, \%\right)$ for green (a) and red (b) filters. 


\section{Control experiments}

In such experiments, a question constantly arises concerning whether the fish acquire discrimination not to color but rather to relative lightness. With an aim to rule out such a possibility, the fish, which were already trained and had reached the discrimination criterion, were presented with pairs for differentiation in which the green stimulus was substituted by an achromatic (gray) stimulus. The gray stimuli were selected in such a way that in one pair, lightness of the gray stimulus was higher than that of the lightred, whereas in some pairs, it was lower. Besides, completely achromatic pairs were presented as well-for example, dark-gray against light-gray.

Studies of the discrimination capacity in conditions when the light mixture has a changing content also require a clarification of the problem if the sharp alteration of illumination affects the capacity of the fish for visual discrimination. Bearing this in mind, in the third series of experiments, in which the stimuli devoid of color properties were presented, the fish were trained to discriminate between a black cross $(10 \times 10 \mathrm{~cm})$ and a black circle $(10 \mathrm{~cm}$ diameter $)$ on a white background. The cross pattern served as a positive stimulus. In all the other details, the experiments of the third series repeated the scheme of the previous series.

The number of choices in the training (white illumination) and testing (mixed red/green illumination) were summed separately for the given mixture illumination conditions for the four fish. The sums were plotted as the relative choice frequency in percent against the number of trials (see Figs. 4, 9) or against the given red/green light ratio in the mixture (see Figs. 5, 6, 8, 10). All data were considered in the analysis.

In all series of experiments, the differences between the groups were considered statistically significant when the hypothesis on random distribution was repudiated with a significance level of 0.05 , using the Student's t-test.

\section{RESULTS}

First, it should be noted that altering the general illumination, either toward its reduction or amplification, did not influence the test results in any series of experiments.

As shown in Figs. $4 a$ and $4 b$, under the conditions of our experiments, the fish achieved statistically reliable discrimination $(>70 \%$ of correct choices) with white illumination after about 250 trials.

The results of Group I obtained in the second series of experiments (illumination with a redgreen light mixture) are shown in Fig. 5. Clearly, a significant level of discrimination was achieved when the red/green ratio in the mixture was $2 \mathrm{r} / 9 \mathrm{~g}$ (18\% red and $82 \%$ green).

The results of Group II are shown in Fig. 6. In this case, when the animals were kept under a constant source of illumination, a much higher share of red light in the mixture was required for achieving a significant discrimination level-the threshold red/green ratio was $3 \mathrm{r} / 9 \mathrm{~g}$ (25\% red and $75 \%$ green).

The results of the control experiments using gray stimuli are shown in Table 1. Obviously, substituting a green stimulus for a gray one did not influence the significance of the red stimulus choice, whereas when both stimuli were achromatic and the difference was solely lightness-dependent, the choice was made at a random level. This result indicates that the fish fulfill discrimination specifically by color, with the red stimulus serving as a reinforced one.

Following the termination of this series, fish of Group II were transferred into natural illumination conditions. Figure 7 demonstrates the test results of Group 2 two months after they had been living 

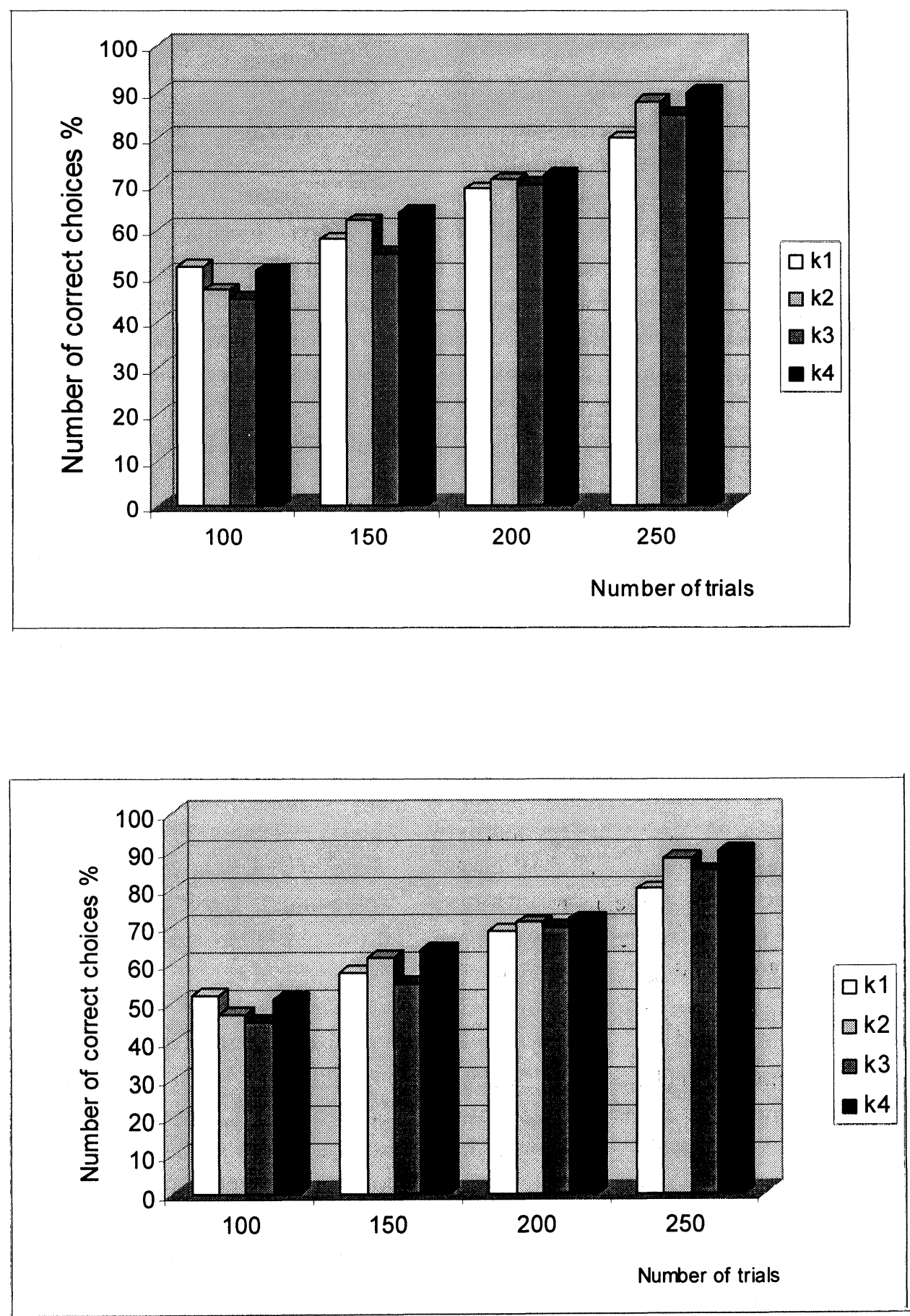

Fig. 4: The first series of experiments. Learning dynamics in four animals of the Group I (a) (upper), and in four animals of the Group II (b) (lower). On the abscissa - number of trials, on the ordinate - percentage of correct choices calculated per sum of trials. Total number of trials for each fish during the training: $n=250$. The numerals on the columns $(1,2,3,4)$ represent numbers of fish. 


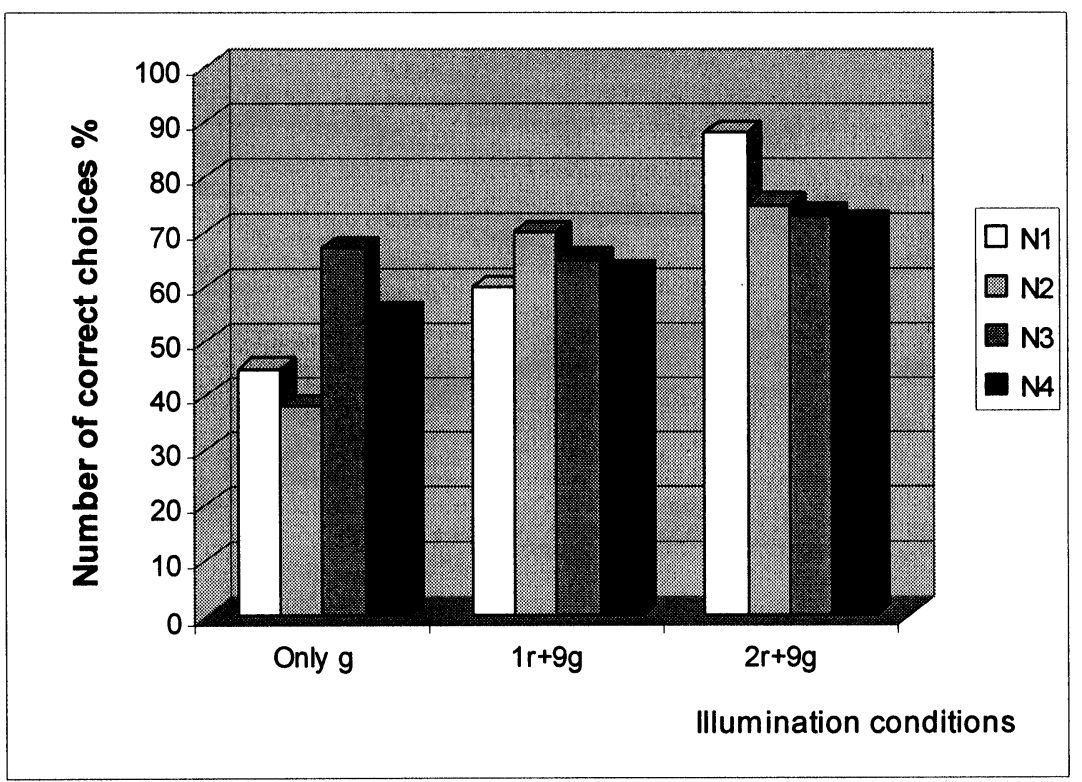

Fig. 5: The second series of experiments. Results of the testing in four animals of Group I. On the abscissa - ratio red (r) and green (g) lights in the mixture. On the ordinate - percentage of correct choices per total number of trials with given mixture. Total number of choices for each fish in given condition of illumination (only $\mathrm{g}$; $1 \mathrm{r}+9 \mathrm{~g}$; $2 r+9 g): n=100$. Significance level $<0,05$. The numbers on the columns $(1,2,3,4)$ represent numbers of fish.

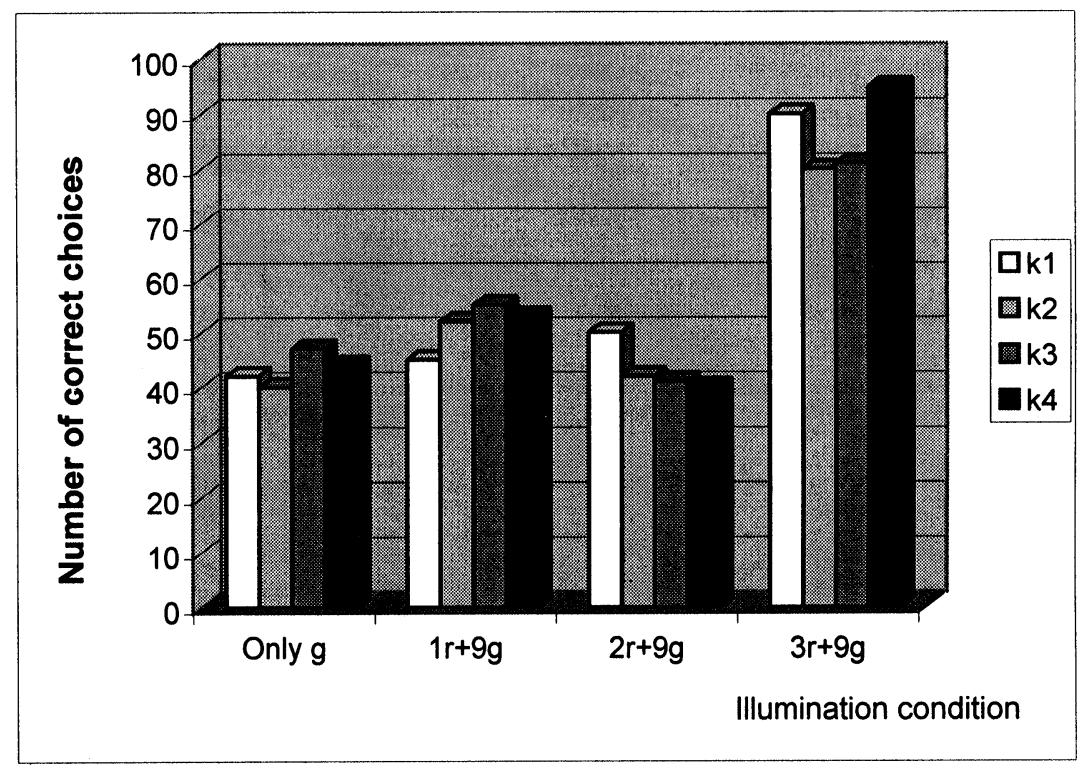

Fig. 6: The second series of experiments. Results of the testing in four animals of Group II. On the abscissa - ratio red (r) and green $(\mathrm{g})$ lights in the mixture. On the ordinate - percentage of correct choices per total number of trials with given mixture. Total number of choices for each fish in given condition of illumination (only $\mathrm{g} ; 1 \mathrm{r}+9 \mathrm{~g} ; 2 \mathrm{r}+9 \mathrm{~g}$; $3 r+9 g): n=100$. Significance level $<0,05$. The numbers on the columns $(1,2,3,4)$ represent numbers of fish. 
TABLE 1

Percentage of correct choices on Color vs. Gray pairs in different conditions of illumination $^{1}$

\begin{tabular}{|c|c|c|c|}
\hline \multirow{2}{*}{$\begin{array}{c}\text { Fish } \\
\text { number }\end{array}$} & \multicolumn{3}{|c|}{$\begin{array}{c}\text { Pairs of stimuli } \\
\text { (illumination) }\end{array}$} \\
\cline { 2 - 4 } & $\begin{array}{c}\text { Dark Gray-Light Gray } \\
\text { (white) }\end{array}$ & $\begin{array}{c}\text { Red-Gray } \\
\text { (white) }\end{array}$ & $\begin{array}{c}\text { Red-Gray } \\
\text { (mixed red+green) }\end{array}$ \\
\hline 1 & 50 & 91 & 86 \\
\hline 2 & 53 & 93 & 84 \\
\hline 3 & 50 & 95 & 86 \\
\hline 4 & 57 & 92 & 85 \\
\hline
\end{tabular}

${ }^{1}$ Total number of choices for each fish in given condition of illumination: $n=100$. Significance level $<0,05$.

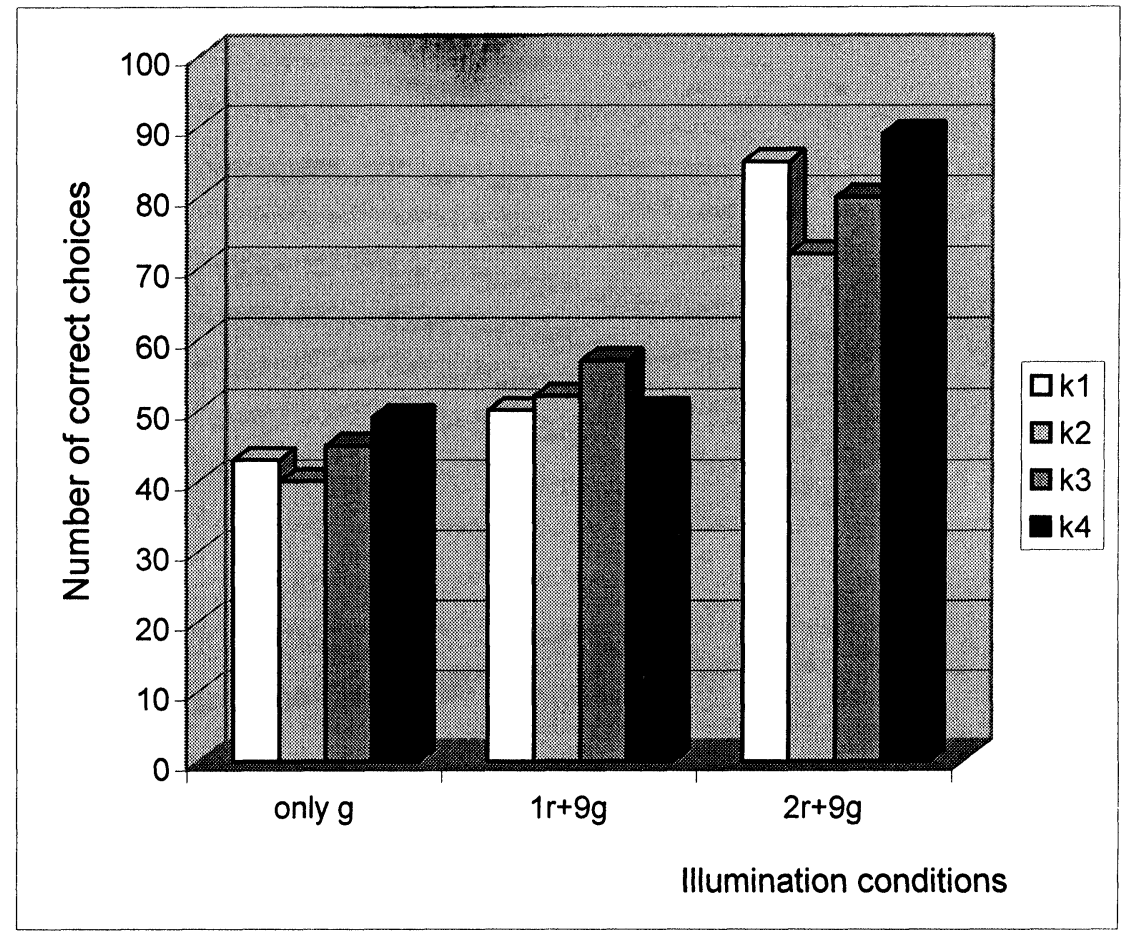

Fig. 7: Results of the testing in four animals of Group II following their transfer into the habitat with natural lighting. On the abscissa - ratio red (r) and green (g) lights in the mixture. On the ordinate - percentage of correct choices per total number of trials with given mixture. Total number of choices for each fish in given condition of illumination (only g; $1 \mathrm{r}+9 \mathrm{~g} ; 2 \mathrm{r}+9 \mathrm{~g}$ ): $\mathrm{n}=100$. Significance level $<0,05$. The numbers on the columns $(1,2,3$, 4) represent number of fish. 


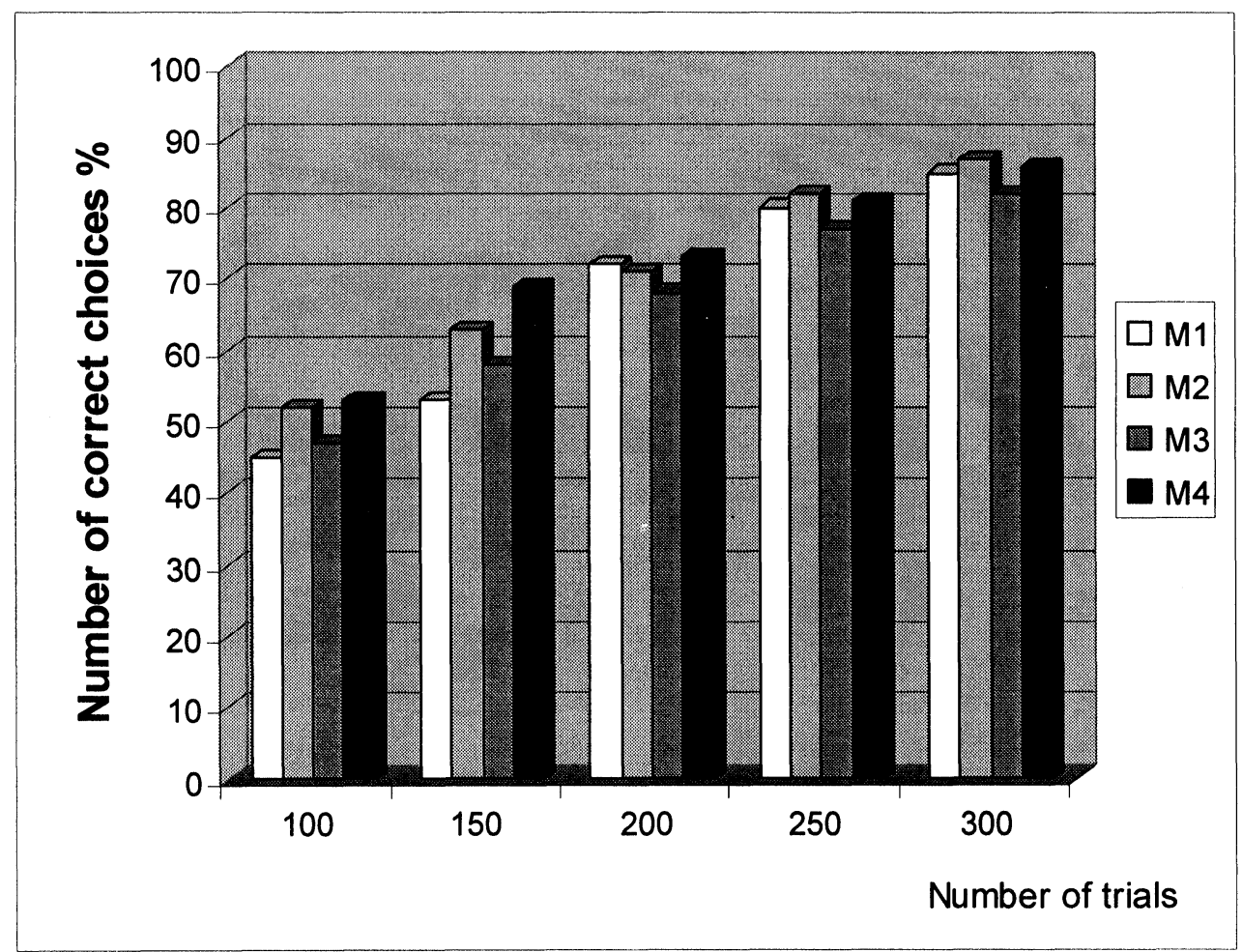

Fig. 8: Learning dynamics during "Cross-Circle" discrimination in the "intact" animals. On the abscissa - number of trials, on the ordinate - percentage of correct choices calculated per sum of trials. Total number of trials for each fish during the training: $n=300$. The numbers on the columns $(1,2,3,4)$ represent numbers of fish.

in the same conditions as those maintained for the animals of Group I. Clearly, almost complete compensation occurred during this time, and the test results are identical to those obtained in the control group.

The third control series of experiments was carried out in fish raised in the same conditions as the animals of Group II, but experimentally naïve. As shown in Fig. 8, the fish reached a statistically significant level of discrimination $(>70 \%$ of correct choices) at standard illumination within about 250 trials. This parameter fully corresponds to the mean results obtained in the other series. After achieving discrimination significance, the testing was made under different illumination conditions. Figure 9 shows the results of discriminations performed at various ratios of red and green light in the mixture. Evidently, altering the content of the mixture had no impact on the discrimination capacity-even at extreme values (for example, illumination with green light only) the discrimination level remained practically unaltered.

\section{DISCUSSION}

Experiments on visual deprivation in different animal systems, as well as observations in children with inborn cataracts, have unequivocally shown that normal development of the visual function requires accumulation of visual experience (Hubel \& Wiesel, 1965; Wiesel \& Hubel, 1965a; Sherman, Spear, 1982; Boothe et al., 1985). Undoubtedly, 


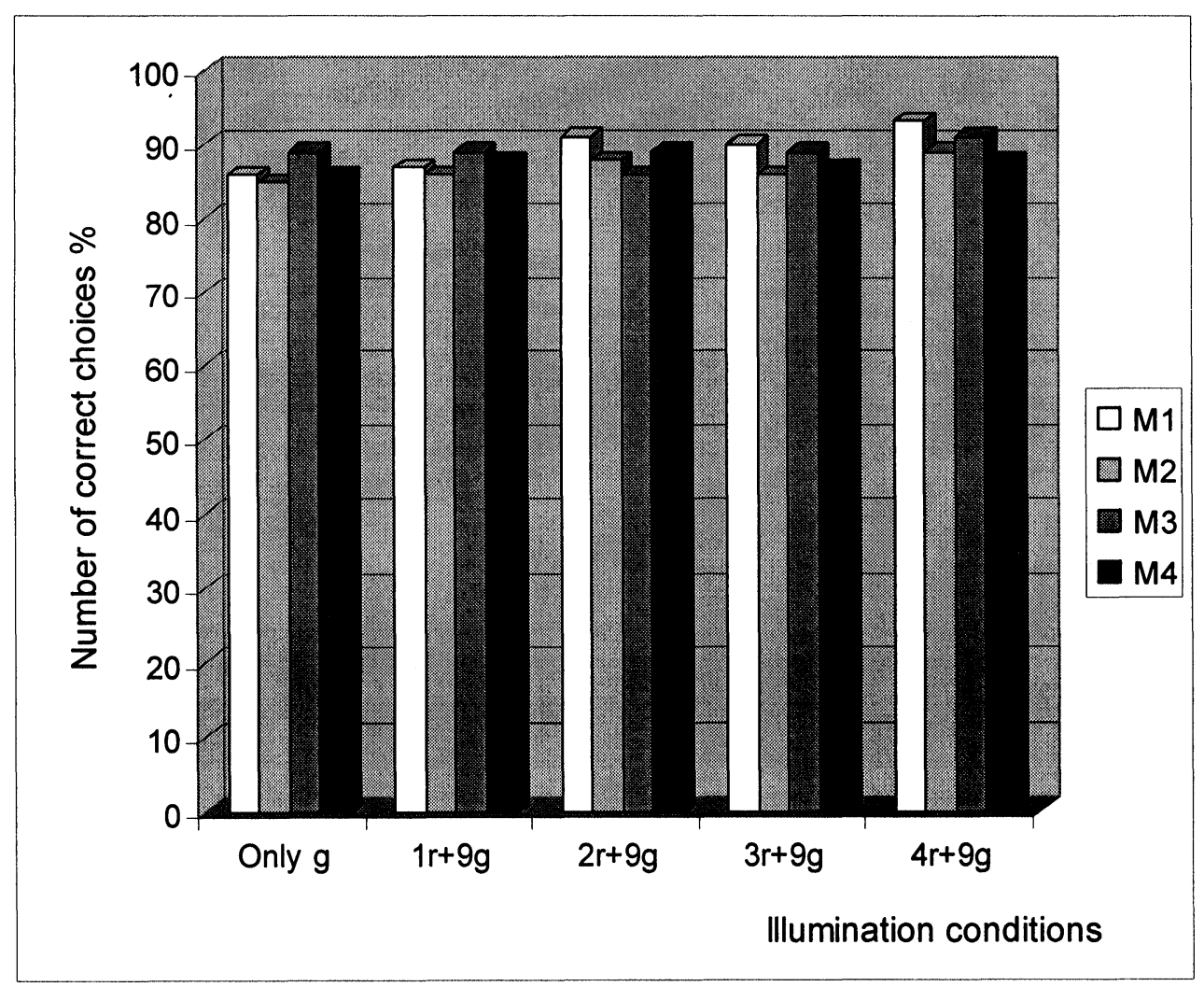

Fig. 9: "Cross-Circle" discrimination. Percentage of correct choices during different ratio of red and green lights made by the fish of the "intact" group. On the abscissa - ratio red ( $\mathrm{r}$ ) and green ( $\mathrm{g}$ ) lights in the mixture. On the ordinate - percentage of correct choices per total number of trials with given mixture. Total number of choices for each fish in given condition of illumination (only $g ; 1 r+9 g ; 2 r+9 g ; 3 r+9 g ; 4 r+9 g$ ): $n=100$. The numbers on the columns $(1,2,3,4)$ represent numbers of fish.

the formation of the nervous pathways necessary for the perception of shape, space, and motion occurs in the postnatal period under the control of the visual system proper (Wiesel \& Hubel, 1965b; Movshon \& Van Sluyters, 1981). Evidently, the final formation of different functions of the visual system is determined by peculiarities of the pre- and postnatal development, namely, by internal and external factors, as well as by individual sensory experience.

In the process of recognizing the color object in the underwater world, the visual system encounters additional problems. Unlike the almost transparent air, water is characterized by essential peculiarities of light diffraction and absorption. Distinct from terrestrial animals that can recognize a color solely by spectral content of a source and by reflecting the property of an object's surface, water animals must also consider light absorption and diffraction in the water on its way from the light source to an object and from an object to the retina. Notwithstanding such complications, the visual system of fish can assess and consider all the parameters concerned with the correct color recognition of an object's surface.

The functioning of the visual system in the natural habitat is constantly challenged by the task 
of color recognition under various conditions of illumination. Meanwhile, this capacity, in our opinion, belongs to the visual system-response function, the execution of which requires training of the system. Multiple alterations in the spectral content of the light source observed in real life are a major, if not the only, factor under the influence of which perfect color perception development must proceed.

The results of our experiments certify that the differences obtained in the animals of both groups are linked neither with the level nor with the spectral content of illumination in the experimental aquarium. The animals bred and raised under a constant source of light clearly differed from the control group because for correct recognition of a color at mixed illumination, each needed a different red/green ratio in the mixture. In turn, this result might indicate that the capacity for developing respective compensatory and correction shifts is formed during color recognition tasksolving under different conditions of illumination.

On the other hand, the results of our study also indicate that the sensitive period is not critical in restrictions of this kind. Transferring the fish into normal conditions of illumination and the further accumulation of individual experience under new conditions allow the solution of the task with gradually increasing efficiency. In about 2 months, the animals of this control group basically did not differ from those in the experimental groups.

As a concluding remark, it could be said that apparently a capacity for color constancy, which definitely is genetically determined, is realized with the mechanisms that are finally formed during postnatal development. The efficiency of such mechanisms is promoted by the accumulation of an individual sensory (visual) experience. Accumulation of visual experience may be carried out both in the early postnatal period of individual development and after its termination.

\section{REFERENCES}

Boothe R, Teller DY, Sackett GP. 1975. Trichromacy in normally reared and light deprived infant monkeys (Macaca nemestrina). Vision Res 15, 1187-1191.

Boothe R, Dobson V, Teller DT. 1985. Postnatal development of vision in human and nonhuman primates. Annu Rev Neurosci 8: 495-545.

Brenner E, Cornelissen F, Nuboer W. 1990. Striking absence of long lasting effects of early color deprivation on monkey vision. Dev Psychobiol 23: 441-448.

Brenner E, Saan JP, Wortel JF, Nuboer JW. 1983. Early color deprivation in pigeon. Behav Brain Res 8: 343-350.

Brenner E, Schevilis J, Nubeoer JW. 1985. Early colour deprivation in monkey (macaca fascicularis). Vis Res 25, 1337-1339.

Brown AM. 1990. Development of visual sensitivity to light and color vision in human infants: a critical review. Vis Res 30: 1159-1188.

Brown AM., Teller DY. 1989. Chromatic opponency in 3-month-old human infants. Vis Res 29: 37-45.

Burkamp W. 1923. Versuche uber das Farbenwiedererkennen der Fische. Z Sinnesphysiol 5: 133--170.

Di S, Nietz J, Jacobs GH. 1987. Early color deprivation and subsequent color vision in a dichromatic monkey. Vis Res 27: 2009-2031.

Dimentman AM, Karas AY, Maximov VV, Orlov OY. 1972. Constancy of object color perception in the carp (Ciprinus carpo). Pavlov J Higher Nerv Act 22: 772-779. [in Russian].

Dörr S, Neumeyer C. 1997. Simultaneous color contrast in goldfish-a quantitative study. Vis Res 37 : 1581-1593.

Dörr S, Neumeyer C. 2000. Color constancy in goldfish: the limits. J Comp Physiol A 186: 885-896.

Endler JA. 1978. A predator's view of animal color patterns. Evol Biol 11: 319-364.

Endler JA. 1983. Natural and sexual selection on color patterns in Poeciliid fishes. Environ Biol Fishes 9: 173-190.

Herter K. 1950. Uber simultanen Farbkonstant bei Fischen. Biol Zentralbl 69: 283-300.

Hubel DH, Wiesel TN. 1965. Binocular interaction in striate cortex of kittens reared with artifical squint. J. Neurophysiol 28: 1041-1059. 
Ingle DJ. 1985. The goldfish as retinex animal. Science 227: $651-654$

Jacobs GH, Neitz J. 1984. Development of spectral mechanisms in the ground squirrel retina following lid opening. Exp Brain Res 55: 507-514.

Kröger RHH, Bowmaker JK, Wagner HJ. 1999. Morphological changes in the retina of Aequidens pulcher (Cichlidae) after rearing in monochromatic light. Vis Res 39: 2441-2448.

McCourt ME., Jacobs GH. 1983. Effects of photic environment on the development of spectral response properties of optic nerve fibers in ground squirrel. Exp Brain Res 49: 443-452.

Mecke E. 1983. Absence of changes in colour discrimination ability of goldfish when reared in monochromatic light. Acta Zool Fennica 20: 239244.

Movshon JA, Van Sluyters RC. 1981. Visual neural development. Annu Rev Psychol 32: 477-522.

Neumeyer C, Dörr S, Fritsch J, Kardelky C. 2002. Colour constancy in goldfish and man: influence of surround size and lightness. Perception 31: $171-187$.

Peterson N. 1961. Effects of monochromatic rearing on the control of responding by wavelength. Science 136: 774-775.

Petry HM, Kelly JP. 1991. Psychophysical measurement of spectral sensitivity and color vision in red-lightreared tree shrews (Tupaia belangeri). Vis Res 31 : 1749-1757.

Sherman SM, Spear PD. 1982. Organization of visual pathways in normal and visually deprived cats. Physiol Rev 62: 738-855.

Teller DY, Bornstein MH. 1987. Infant color vision and color perception. In: Salapatek $\mathrm{P} \&$ Cohen LB, Eds, Handbook of Infant Perception. Vol. 1. From Sensation to Perception. Orlando, Florida, USA: Academic Press; 185-236.

Wheeler TG. 1982. Color vision and retinal chromatic information processing in teleosts: a review. Brain Res Rev 4. 177-235.

Wiesel TN, Hubel DH. 1965a. Comparison of the effects of unilateral and bilateral eye closure on cortical unit responses in kittens. J Neurophysiol 28: 1029-1040.

Wiesel TN, Hubel DH. 1965b. Extent of recovery from the effects of visual deprivation in kittens. J Neurophysiol 28: 1060-1072. 

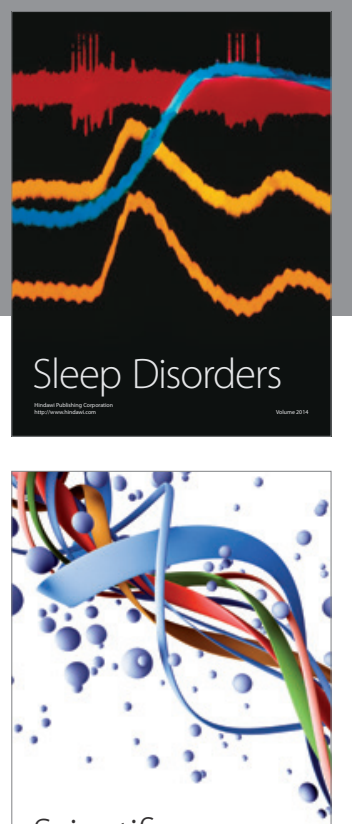

Scientifica
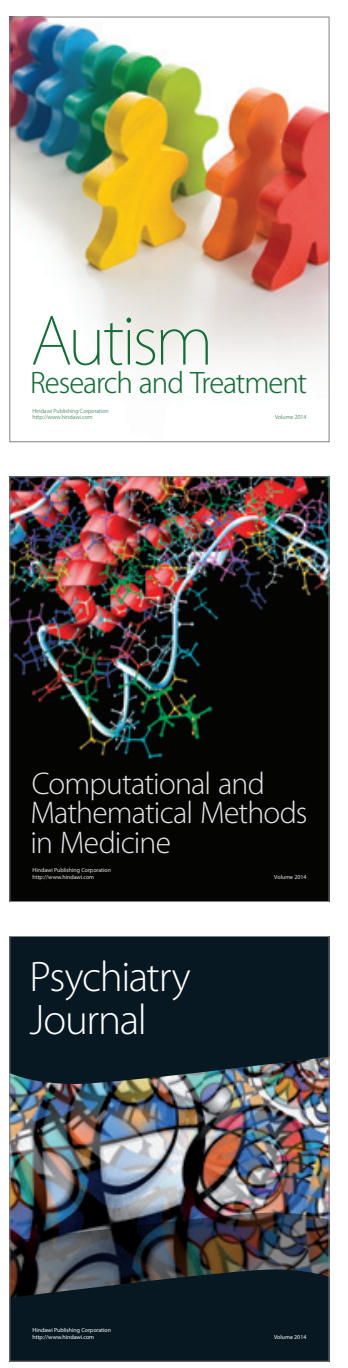
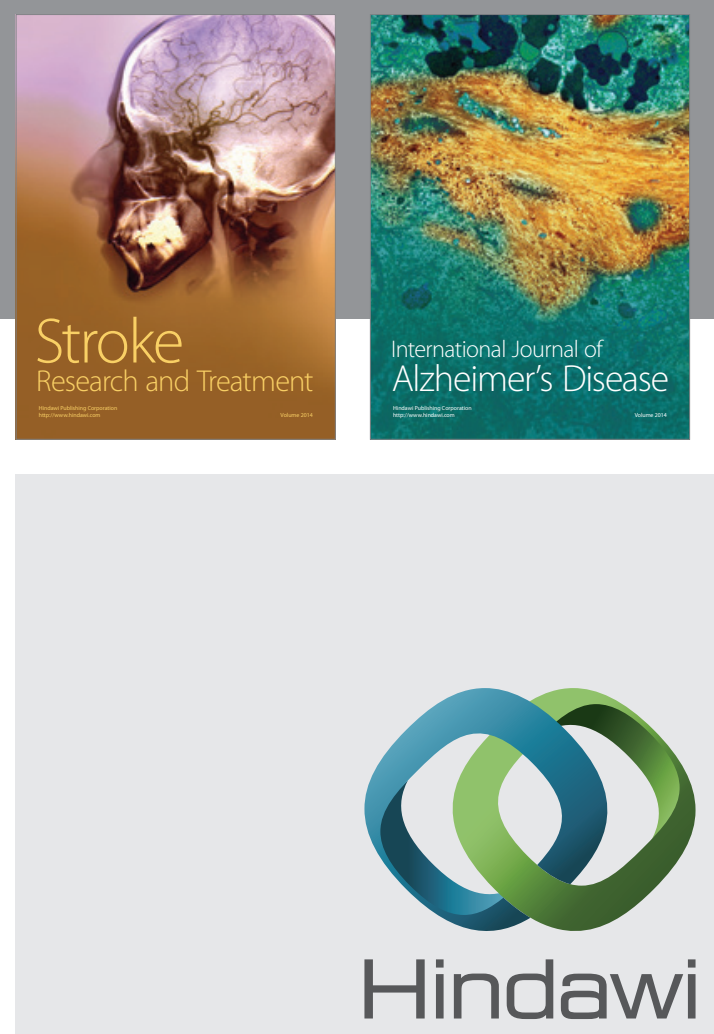

Submit your manuscripts at

http://www.hindawi.com
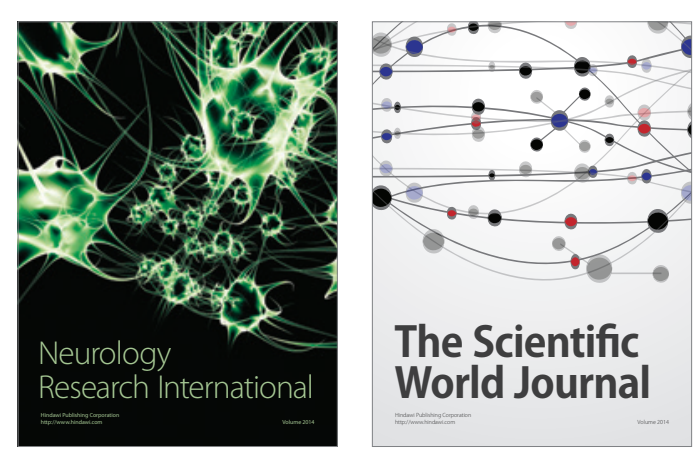

The Scientific World Journal

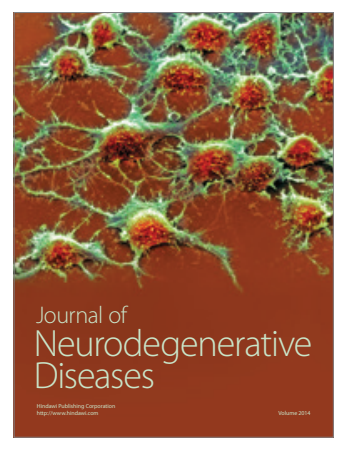

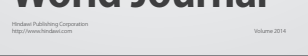

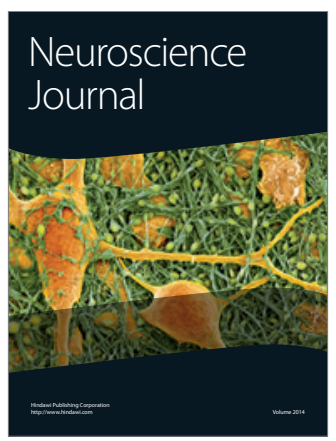

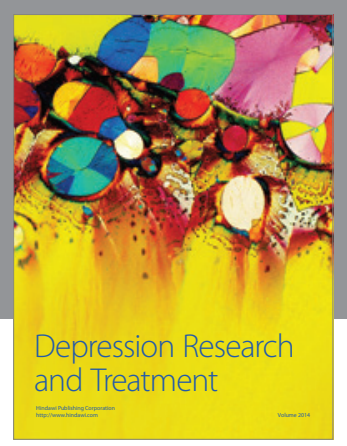
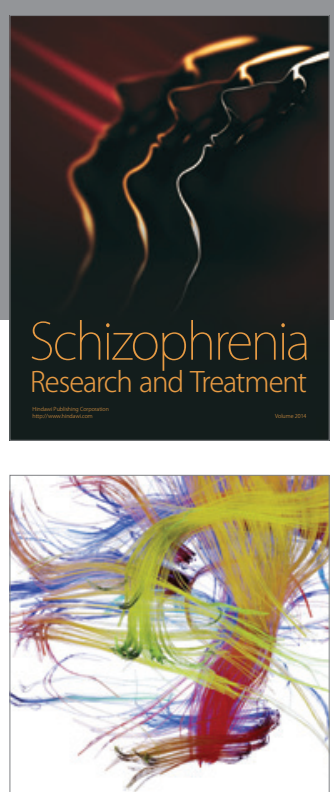

Brain Science

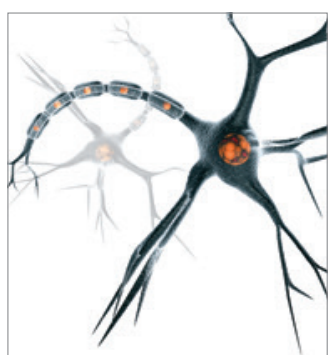

Neural Plasticity
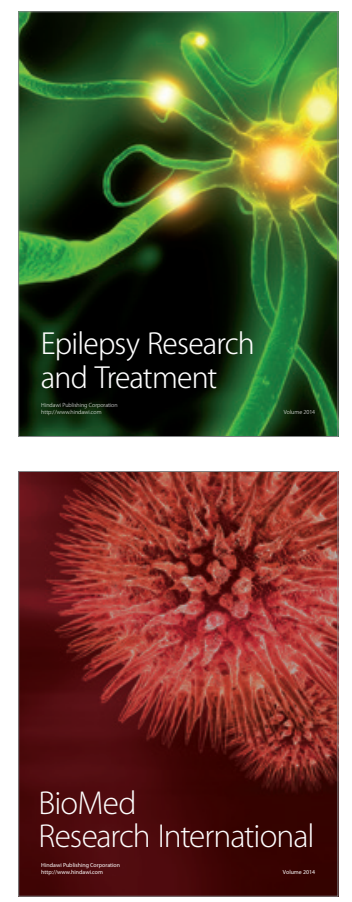

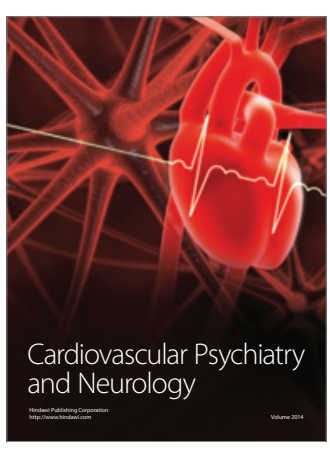

Parkinson's

Disease
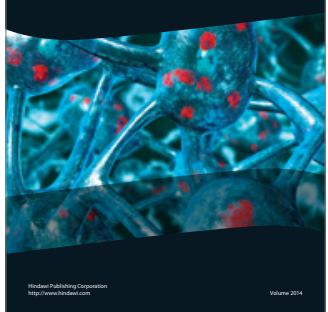